\title{
Effectiveness of the National Program of Complementary Feeding for older adults in Chile on vitamin B12 status in older adults; secondary outcome analysis from the CENEX Study (ISRCTN48153354)
}

Hugo Sanchez ${ }^{1}$, Cecilia Albala ${ }^{1 *}$, Lydia Lera ${ }^{1}$, Alan D Dangour ${ }^{2}$ and Ricardo Uauy ${ }^{1}$

\begin{abstract}
Background: Older people are at increased risk of vitamin B12 deficiency and the provision of fortified foods may be an effective way to ensure good vitamin B12 status in later life.

Aim: To evaluate the effectiveness of a vitamin B12 fortified food provided by a national program of complementary food for older people on plasma vitamin B12 levels.

Subjects and methods: A random sub-sample of 351 subjects aged 65-67y from a large cluster randomised controlled trial provided blood samples at baseline and after 24 months of intervention. The intervention arm (10 clusters 186 participants) received a vitamin B12 fortified food designed to deliver $1.4 \mu \mathrm{g} /$ day, while the control arm did not receive complementary food (10 clusters, 165 participants). Serum vitamin B12 and folate levels determined by radioimmunoassay were used to estimate the effect of intervention on vitamin B12 levels, adjusting for baseline levels and sex.
\end{abstract}

Results: Attrition at 24 months was $16.7 \%$ and $23.6 \%$ in the intervention and control arms respectively ( $p=0.07$ ). Over 24 months of intervention, mean (95\% Cl) serum vitamin B12 decreased from 392 (359-425) pmol/dL to 357 (300-414) $\mathrm{pmol} / \mathrm{dL}(\mathrm{p}<0.07)$ in the intervention arm and from 395 (350-440) pmol/dL to 351 (308-395) pmol/dL in the control arm. There was no significant effect of the intervention on folate status.

Discussion: Our findings suggest that foods fortified with $1.4 \mu \mathrm{g} /$ daily vitamin B12 as provided by Chile's national programme for older people are insufficient to ensure adequate vitamin B12 levels in this population. Chile has a long and successful experience with nutrition intervention programs; however, the country's changing demographic and nutritional profiles require a constant adjustment of the programs.

Keywords: Older people, Fortified foods, Nutrition programme, Vitamin B12

\footnotetext{
*Correspondence: calbala@uchile.cl

'Nutrition and Public Health, Aging, and Genetic Epidemiology Unit, Institute of Nutrition and Food Technology, University of Chile, Avda. El Libano 5524, Casilla 138-11, Santiago, Chile

Full list of author information is available at the end of the article
} 


\section{Introduction}

The ageing process of the Chilean population involve multiple repercussions on public health [1,2]. The gradual deterioration of physical and mental health conditions that accompanies ageing is a result of genetic and environmental interactions, including lifestyle, dietary habits, physical activity, and the presence of disease. Nutrition plays an important role in modulating changes induced by aging on various organ and body functions. Older people are vulnerable to multiple micronutrient deficiencies, especially vitamin B12 [3].

Vitamin B12 (B12) and folic acid are essential dietary constituents that regulate key metabolic pathways required for myelin and neurotransmitter synthesis; they also contribute to red blood cell replication and maturation [4].

Liver B12 stores are sufficient to meet adult needs for several months since daily requirements are low $(2.4 \mu \mathrm{g} /$ day) and manifestations of deficiency are apparent only after an extended dietary inadequacy (1 to 2 years) [5].

In Chile, the prevalence of B12 deficit in older adults is high with estimates ranging from $25.4 \%$ to $54.1 \%$ [6-8]. The prevalence is greater in men than women [6] and increases with advancing age [5].

In 1998 the Chilean Ministry of Health established a program for older adults designed to maintain health and activity levels in later life, reduce acute morbidity and functional decline, and decrease health inequalities $[9,10]$. The program includes health promotion, illness prevention, and poverty reduction initiatives [11], and a complementary feeding program for older people (called PACAM) [12], which aims to promote adequate nutrition across the life course. Since 1999, PACAM has delivered foods to adults over the age of 69 who are beneficiaries of the National System of Health Services [13] providing $1.7 \mathrm{ug} /$ day of vitamin B12. Since 2000, wheat flour has been mandatorily fortified in Chile with 2.0-2.4 mg Folic Acid/Kg. Bread is an important food staple in Chile and this programme is estimated to deliver $200-400 \mu \mathrm{g}$ of folate per day to older people [14,15].

The primary objective of this study was to evaluate the effectiveness of the national complementary feeding program for older people (PACAM) on serum B12 levels in older adults. Secondary outcomes of interest include serum folate levels and relevant haematological parameters.

\section{Subjects and methods}

This is a sub-study of the CENEX study [16] which was a cluster randomised controlled trial design to evaluate the cost effectiveness of a 2-y nutritional supplementation (PACAM) and/or physical activity program delivered at the community level to 2799 eligible subjects aged 65.0-67.9 y in a factorial design with four distinct study arms: Nutrition intervention (PACAM) alone,
Exercise alone, Nutrition plus exercise and Control [17]. Exclusion criteria of the CENEX study included unable to walk unaided, unplanned 3-kg weight loss over 3 months, planning to move house within 12 months, already enrolled in the national PACAM program or reporting a current consumption of PACAM program supplement and cognitive impairment defined as a score $<13$ using a 19-item Mini Mental State Examination (MMSE) [18] and scoring $<6$ in the PfefferActivities) $[19,20]$.

At baseline, socioeconomic characteristics, history of chronic diseases and self-reported health status (SRH) were registered. Anthropometric measurements and physical performance were assessed as previously described [17]. A sub-sample of 125 randomly selected participants per group was invited for the assessment of blood indicators under fasting conditions. Blood samples were obtained from 491 individuals at baseline and from 394 participants after 2-y of intervention. The CENEX study was approved by ethics committees at Institute de Nutrition and Technology of Foods (INTA; University of Chile), Ministry of Health (Government of Chile), and London School of Hygiene \& Tropical Medicine (LSHTM; University of London). All study participants provided full informed written consent before being enrolled in the study.

The intervention comprised $1 \mathrm{~kg} /$ month of a dried soup powdered (made of a mixture of grains and vegetables) and $1 \mathrm{~kg} /$ month of a powdered milk drink (made of low-lactose milk), both of which were fortified with vitamins and minerals (Table 1 ). The recommended daily dose is $25 \mathrm{~g} /$ day of dried soup and $50 \mathrm{~g} /$ day powered milk, both products providing jointly $1.7 \mathrm{ug} /$ day of vitamin B12; approximately $58 \%$ of the daily reference nutrient intake (2.4 $\mu \mathrm{g} /$ day) $[21]$.

Fasting venous blood sample were collected by study nurses. All blood samples were stored at $-80^{\circ} \mathrm{C}$ and processed at the end of the study. The serum B12 and folate levels were determined in duplicate using radioimmunoassay (Dual Count Solid phase no boil Assay Siemens, LA). The red blood cell analysis included haemoglobin (Hb; g/dL), haematocrit (Hct;\%), and median corpuscle volume (MCV; $\mathrm{fL}$ ); these parameters were determined using an electronic particle counter (Cell-Dyn Model 1700 (Abbott Diagnostics, Abbott Park, IL).

\section{Statistical analysis}

We evaluated the groups' compliance with PACAM intake by counting the number of PACAM products retrieved monthly from the health centre, with 12 retrievals considered 100\% compliance (i.e., the collection of $2 \mathrm{~kg}$ in 12 of $24 \mathrm{mo}$ ), as systematically documented in the records kept by health centre auxiliary nurses.

The reference values proposed by Allen et al. [22] were used to categorise B12 status as deficient $<148 \mathrm{pmol} / \mathrm{dL}$, as subclinical deficient with levels between 148 and 221 
Table 1 Nutritional composition of fortified foods

\begin{tabular}{|c|c|c|c|c|}
\hline \multirow{3}{*}{$\begin{array}{l}\text { Nutrient } \\
\text { content per } \\
\text { serving }\end{array}$} & \multicolumn{2}{|c|}{ Cream soup } & \multicolumn{2}{|c|}{ Milk drink } \\
\hline & \multirow[t]{2}{*}{$100 \mathrm{~g}$} & $\begin{array}{c}1 \text { SERVING } \\
(50 \mathrm{~g})\end{array}$ & \multirow[t]{2}{*}{$100 \mathrm{~g}$} & \multirow{2}{*}{$\begin{array}{c}1 \text { SERVING } \\
(25 \mathrm{~g}) \\
\% \text { RDA }^{*}\end{array}$} \\
\hline & & $\%$ RDA* $^{*}$ & & \\
\hline Energy Kcal & $400.0 \mathrm{kcal}$ & - & 400.0 & - \\
\hline Protein $\mathrm{g}$ & 13.0 & - & 18.0 & - \\
\hline lipids $g$ & 11.0 & - & 10.0 & - \\
\hline linoleic acid g & - & & 1.8 & - \\
\hline Carbo-hydrates $\mathrm{g}$ & 62.3 & - & 59.5 & - \\
\hline Total dietary fiber $\mathrm{g}$ & 6.2 & - & 1.0 & - \\
\hline \multicolumn{5}{|l|}{ VITAMINS } \\
\hline Vitamin A (ug RE) $^{1}$ & 240.0 & 15 & 800.0 & 25 \\
\hline$\overline{\text { Vitamin D }(\mathrm{ug})^{2}}$ & 1.5 & 15 & 16.0 & 80 \\
\hline$\overline{V i t a m i n} \mathrm{E}(\mathrm{mg} \mathrm{TE})^{3}$ & 4.0 & 20 & 32.0 & 40 \\
\hline Vitamin C (mg) & 30.0 & 25 & 180.0 & 75 \\
\hline Vitamin B1 (mg) & 0.35 & 12.5 & 0.8 & 14 \\
\hline Vitamin B2 (mg) & 0.40 & 12.5 & 1.6 & 25 \\
\hline Niacin (mg) NE ${ }^{4}$ & 4.5 & 12.5 & 10.0 & 14 \\
\hline Vitamin B6 (mg) & 1.0 & 25 & 1.6 & 20 \\
\hline Folate (ug) & 100.0 & 25 & 80.0 & 10 \\
\hline Vitamin B12 (ug) & 1.4 & 25 & 2.8 & 70 \\
\hline \multicolumn{5}{|l|}{ MINERALS } \\
\hline Calcium (mg) & 400.0 & 25 & 1000.0 & 31 \\
\hline Phosphorus (mg) & 400.0 & 25 & 800.0 & 25 \\
\hline Magnesium (mg) & 150.0 & 25 & 300.0 & 25 \\
\hline Iron (mg) & 5.0 & 25 & 5.6 & 10 \\
\hline Zinc (mg) & 6.0 & 25 & 12.0 & 20 \\
\hline
\end{tabular}

$\mathrm{pmol} / \mathrm{dL}$, and as normal with levels $>221 \mathrm{pmol} / \mathrm{dL}$. We excluded participants from analysis of B12 status if they presented with baseline $\mathrm{B} 12$ values $>680 \mathrm{pmol} / \mathrm{L}$, as such levels suggest that the participants used vitamin supplements [23]. For folate, values below $7 \mathrm{nmol} / \mathrm{L}$ were considered deficient, 7 to $46 \mathrm{nmol} / \mathrm{L}$ as normal, and values $>46 \mathrm{nmol} / \mathrm{L}$ as supraphysiological levels $[23,24]$. The diagnosis of anaemia was made for haemoglobin values $<13 \mathrm{~g} / \mathrm{dL}$ in men and $<12 \mathrm{~g} / \mathrm{dL}$ in women [7]. Microcytosis and macrocytosis were considered for values $<80 \mathrm{fL}$ and $>100 \mathrm{fL}$, respectively [25].

The five self-reported health status (SRH) response categories were regrouped into good (excellent, very good and good) fair and poor.

At baseline and post-intervention, mean $(95 \% \mathrm{CI})$ or median (IQR: p25-p75) plasma levels and status (percentage, $95 \% \mathrm{CI}$ ) of B12 and folates are reported.

The differences between baseline and post-intervention mean plasma levels of B12 and folate are reported as mean differences and 95\% CI adjusted for baseline levels and accounting for the clustered design in an intention to treat analysis. The statistical significance of the differences was analysed by Wald Test. All statistical analyses were carried out in STATA 12.0.

\section{Results}

From the 491 subjects initially evaluated, 490 blood samples allowed the measurement of vitamin B12 levels, from which 351 met the inclusion criterion for plasma B12 levels <680 pmol/dL: 186 (28\% male) in the intervention arm and 165 (30.9\% male) in the control arm. At 24 months, 31 participants from the PACAM group (16.7\%) were lost to attrition, and 39 were lost from the control group $(23.6 \%)(\mathrm{p}=0.07)$. A flow diagram is shown in Figure 1.

Participants collected $68 \%$ of total available food and adherence was $75 \%$. Only one person did not comply at all and $61,6 \%$ complied most of the time.

The baseline characteristics split by arm of intervention and gender are presented in Table 2. The intervention and control arms were well matched for age, gender, educational attainment, self-perception of health and haematological parameters at baseline.

In Table 3 baseline and final levels of B12 and folates are shown, along with the mean and $95 \% \mathrm{CI}$ of the serum levels of $\mathrm{B} 12(\mathrm{pmol} / \mathrm{L})$ and folates $(\mathrm{nmol} / \mathrm{L})$ by gender. B12 levels were significantly lower in men than women, both in the PACAM group $(\mathrm{p}=0.02)$ and the control group $(p=0.05)$. No differences in serum B12 levels at baseline neither at 24 months were observed between PACAM and control groups. Serum B12 levels decreased between baseline and 24 months only in men in both PACAM $(-39.4, \mathrm{p}<0.01)$ and control $(-57.3, \mathrm{p}<0.06)$. No difference in the magnitude of the decrease between both groups was observed.

No differences in serum folate levels at baseline neither at 24 months were observed between PACAM and control groups. Serum folates levels decreased significantly $(\mathrm{p}<0.01)$ between baseline and 24 months in both PACAM $(-8.3 \mathrm{nmol} / \mathrm{L})$ and control $(-7.2 \mathrm{nmol} / \mathrm{L})$ groups, with no differences in the magnitude of the fall between both groups.

Table 4 presents B12 and folate status by category and sex; this shows that the frequency of B12 deficiency was similar in the two groups at baseline and after intervention. After adjusting for sex, age, and baseline B12, the multilevel model indicated no significant change in B12 after intervention for either the PACAM or control groups (data not shown). No folate deficiency at baseline or post-intervention was observed.

In terms of folate, the prevalence of values $>46 \mathrm{nmol} / \mathrm{L}$ was $20.6 \%$ at baseline decreasing to $6.8 \%$ at 24 months. After adjusting for sex, age, and baseline folate, the 


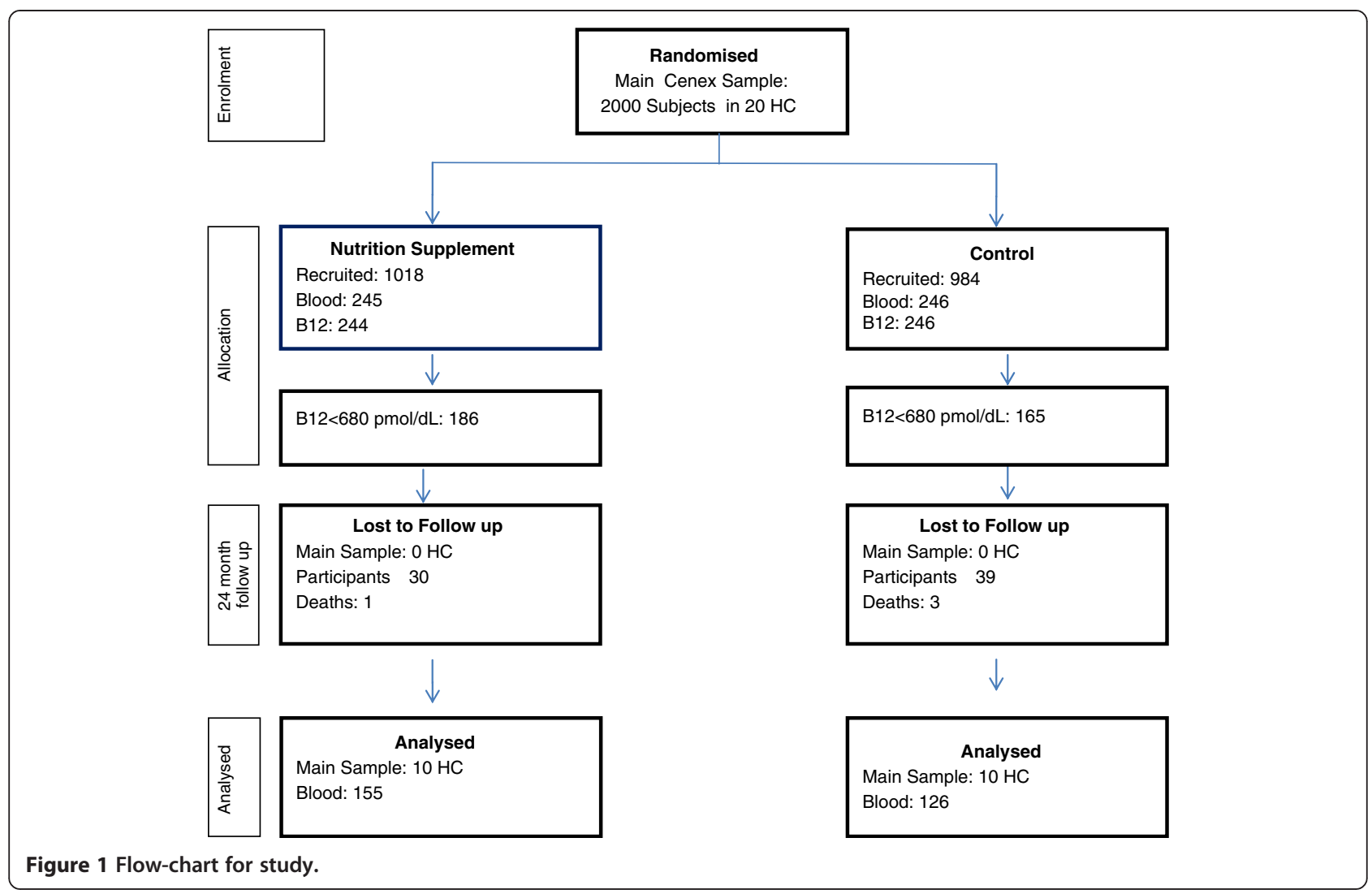

multilevel model indicated a significant change in folate after intervention for either the PACAM or control groups (data not shown).

The prevalence of anaemia was $8.3 \%$ at baseline and $7.5 \%$ at 24 months. Macrocytosis was $0.3 \%$ at baseline, increasing to $2.1 \%$ after intervention.

\section{Discussion}

The results demonstrate that the program did not significantly improve B12 status in comparison with the control group. B12 deficiency is relatively common among older people and is associated with metabolic, haematological, cognitive, and neuroconduction problems [26]. In a study recently published by our group, we found a B12 deficit of $12 \%$ using the cut-off of $<148$ $\mathrm{mpol} / \mathrm{L}$ and $25.4 \%$ using the cut-off of $<221 \mathrm{pmol} / \mathrm{L}$ [6]. Allen obtained similar results in an American population [27] and Loikas in a Turkish population [28].

The possible causes of B12 deficiency in the older adult population fall into two main categories: a) gastric atrophy associated with aging, which impedes the absorption of B12 from foods due to a lack of acid [29,30], along with decreased levels of intrinsic factor, which is an essential element for B12 absorption in the ileum; and b) low intake of B12 containing animal products [31]. Preliminary data from an on-going study [32] suggest that the intake of B12 from foods in older adults is on average $5.4 \mu \mathrm{g} /$ day. The average intake of foods delivered by PACAM is $25 \mathrm{~g}$ /day of powdered milk drink and 3 portions/week of dried soup. Therefore the vitamin B12 intake provided by the programme is about $0.7 \mu \mathrm{g} /$ day, thus resulting in an intake of $6.1 \mu \mathrm{g} /$ day. Therefore, considering the recommended daily requirements $(2.4$ $\mu \mathrm{g} /$ day) for older people it would seem that the deficiency observed in Chile is due primarily to gastric atrophy.

One of the great challenges in nutrition program design at a population level is defining the best course of action for addressing B12 values below the acceptable limit (148 pmol/L).

Studies of a Latino population residing in the United States have demonstrated normalised plasma B12 levels after adding fortified foods or supplements $(\mathrm{F} / \mathrm{S})>500 \mu \mathrm{g} /$ day to the diet. In addition, it has been found that F/S in the crystalline form of the vitamin is the most effective, as it is well absorbed by individuals with and without gastric mucosa atrophy [33].

A possible weakness of this study was that the intake of PACAM products was not specifically quantitated; however, considering that the study was an effectiveness evaluation, no assessment of PACAM intake beyond the usual controls of the program was considered. Another potential weakness was not establishing the usual intake of B12, but Chilean data suggest that the average intake 
Table 2 Baseline characteristics of study groups

\begin{tabular}{|c|c|c|c|c|c|c|}
\hline \multirow[b]{3}{*}{$\mathbf{n}$} & \multicolumn{3}{|c|}{ Pacam } & \multicolumn{3}{|c|}{ Control } \\
\hline & Men & Women & Total & Men & Women & Total \\
\hline & 52 & 134 & 186 & 51 & 114 & 165 \\
\hline \multicolumn{7}{|l|}{ Age } \\
\hline Median (IQR) & $66(65-67)$ & $66(65-67)$ & $66(65-67)$ & $66(65-67)$ & $66(65-67)$ & $66(65-67)$ \\
\hline \multicolumn{7}{|l|}{ Education } \\
\hline $0-5$ years $\%$ & 18.0 & 34.9 & 30.1 & 19.6 & 33.3 & 28.9 \\
\hline $6-10$ years $\%$ & 38.0 & 46.8 & 44.3 & 51.0 & 47.2 & 48.4 \\
\hline$>10$ years $\%$ & 44.0 & 18.2 & 25.6 & 29.4 & 19.4 & 22.6 \\
\hline \multicolumn{7}{|l|}{ Self-reported health status } \\
\hline Good to excellent; $n$ (\%) & $25(50.0)$ & $57(42.5)$ & $83(44.6)$ & $26(51.0)$ & $45(39.5)$ & $71(43.0)$ \\
\hline Fair; n (\%) & $24(46.1)$ & $69(51.5)$ & $93(51.5)$ & $23(45.1)$ & $60(52.6)$ & $83(50.3)$ \\
\hline Poor; n (\%) & 2(3.9) & $8(6.0)$ & $10(5.4)$ & 2(3.9) & $9(7.9)$ & $11(6.7)$ \\
\hline Vitamin B12 (pmol/L) & 337.3 & 408.0 & 386.5 & 355.0 & 414.8 & 385.2 \\
\hline Median (IQR) & $(250.1-438.3)$ & $(279.8-535.2)$ & $(290.2-524.4)$ & $(246.3-474.3)$ & $(294.6-576.7)$ & $(270.9-513.9$ \\
\hline Folate $(\mathrm{nmol} / \mathrm{L})$ & 37.2 & 39.2 & 39.0 & 37.4 & 38.4 & 37.7 \\
\hline Median (IQR) & $(33.7-43.7)$ & $(32.6-43.7)$ & $(32.9-43.7)$ & $(29.6-41.1)$ & $(32.3-42.6)$ & $(31.5-41.7)$ \\
\hline Hct (\%) & 43.7 & 39.0 & 40.1 & 43.7 & 39.6 & 40.6 \\
\hline Median (IQR) & $(41.3-45.3)$ & $(37.0-40.7)$ & $(37.8-42.6)$ & $(41.4-45.8)$ & $(37.6-41.3)$ & $(38.4-42.6)$ \\
\hline $\mathrm{Hb}(\mathrm{gr} / \mathrm{dL})$ & 14.9 & 13.1 & 13.5 & 14.9 & 13.3 & 13.7 \\
\hline Median (IQR) & $(14.0-15.3)$ & $(12.6-13.9)$ & $(12.8-14.4)$ & $(13.8-15.7)$ & $(12.6-13.9)$ & $(12.9-14.5)$ \\
\hline $\mathrm{MCV}(\mathrm{fL})$ & 90 & 89 & 89 & 89 & 89 & 89 \\
\hline Median (IQR) & $(88-93)$ & $(86-91)$ & $(87-91)$ & $(86-92)$ & $(86-91)$ & $(86-92)$ \\
\hline
\end{tabular}

(IQR: p25-p75).

Table 3 Baseline and post-intervention the vitamin B-12 and folates by group and sex

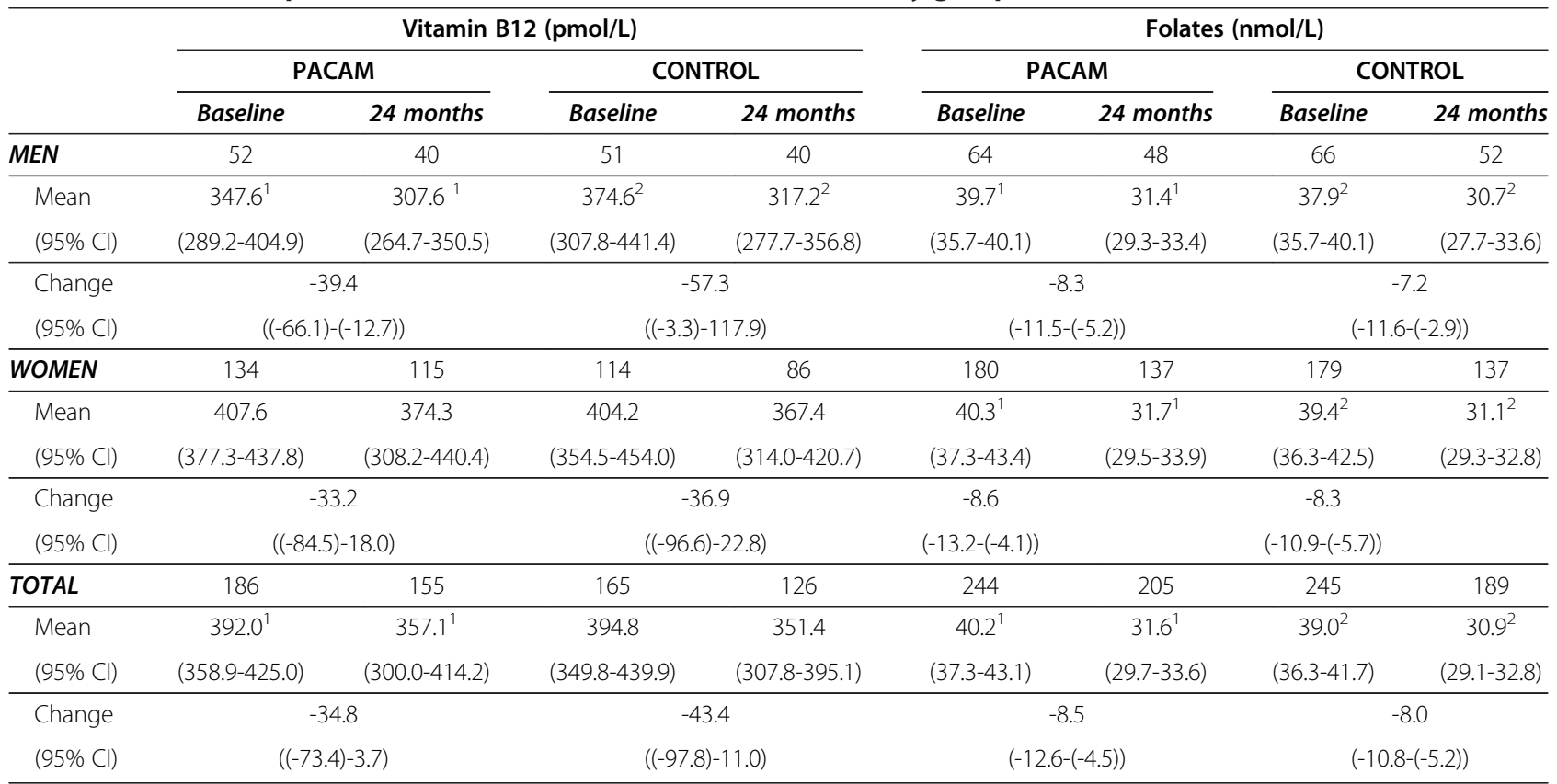

Vitamin B12 $2^{1,2}$ Differences between basal and post-intervention level: ${ }^{1}$ PACAM: Adjusted Wald Test: Men: $p<0.01$; Total $p=0.07 ;{ }^{2}$ CONTROL: Adjusted Wald Test: Men: $p=0.06$. Folates: Differences between basal and post-intervention level: ${ }^{1}$ Adjusted Wald Test $p<0.01 ;{ }^{2}$ Adjusted Wald Test $p=<0.01$. 
Table 4 Vitamin B-12 and folates status before and after intervention, by group and sex

\begin{tabular}{|c|c|c|c|c|c|c|c|c|c|c|c|}
\hline \multicolumn{4}{|c|}{$M E$} & \multicolumn{4}{|c|}{ WOMEN } & \multicolumn{4}{|c|}{ TOTAL } \\
\hline \multicolumn{2}{|c|}{ PACAM } & \multicolumn{2}{|c|}{ Control } & \multicolumn{2}{|c|}{ PACAM } & \multicolumn{2}{|c|}{ Control } & \multicolumn{2}{|c|}{ PACAM } & \multicolumn{2}{|c|}{ Control } \\
\hline \multicolumn{2}{|c|}{$\%$ (Cl 95\%) } & \multicolumn{2}{|c|}{$\%$ (Cl 95\%) } & \multicolumn{2}{|c|}{ \% (Cl 95\%) } & \multicolumn{2}{|c|}{$\%$ (Cl 95\%) } & \multicolumn{2}{|c|}{$\%$ (Cl 95\%) } & \multicolumn{2}{|c|}{$\%(\mathrm{Cl}$ 95\%) } \\
\hline Baseline* & 24 months ${ }^{* *}$ & Baseline* & 24 months ${ }^{* *}$ & Baseline* & 24 months $^{* *}$ & Baseline* $^{*}$ & 24 months ${ }^{* *}$ & Baseline* & 24 months ${ }^{* *}$ & Baseline* & 24 months $^{* *}$ \\
\hline
\end{tabular}

\begin{tabular}{|c|c|c|c|c|c|c|c|c|c|c|c|c|}
\hline \multicolumn{13}{|c|}{ Vitamin B12 (pmol/L) } \\
\hline$n$ & 52 & 40 & 51 & 40 & 134 & 115 & 114 & 86 & 186 & 155 & 165 & 126 \\
\hline \multirow[t]{2}{*}{$<148$} & 13.5 & 7.5 & 7.8 & 7.5 & 9.0 & 7.8 & 7.0 & 9.3 & 10.2 & 7.7 & 7.3 & 8.7 \\
\hline & $(5.1-31.1)$ & $(1.8-26.5)$ & (2.9-19.6) & $(2.6-19.8)$ & $(4.8-15.9)$ & $(2.9-19.3)$ & $(3.2-14.5)$ & $(4.2-19.2)$ & $(5.9-17.2)$ & $(3.4-16.8)$ & $(3.6-14.0)$ & $(4.5-16.2)$ \\
\hline \multirow[t]{2}{*}{$148-221$} & 7.7 & 15.0 & 9.8 & 17.5 & 6.0 & 13.9 & 5.3 & 16.3 & 6.4 & 14.2 & 6.7 & 16.7 \\
\hline & $(4.1-14.0)$ & $(9.3-23.4)$ & $(4.3-20.8)$ & $(9.3-30.4)$ & $(3.4-10.2)$ & (9.0-20.8) & $(3.0-8.9)$ & (9.2-27.2) & $(5.1-8.1)$ & $(9.8-20.2)$ & $(3.6-12.0)$ & $(11.0-24.4)$ \\
\hline \multirow[t]{2}{*}{$222-680$} & 78.8 & 77.5 & 82.3 & 72.5 & 85.1 & 72.2 & 87.7 & 65.1 & 83.3 & 73.5 & 86.1 & 67.5 \\
\hline & (64.7-88.4) & $(59.5-89.0)$ & $(69.2-90.7)$ & $(66.9-77.5)$ & (78.5-89.9) & $(59.6-82.0)$ & $(80.6-92.4)$ & $(49.4-78.1)$ & (76.0-88.8) & $(62.5-82.3)$ & $(79.4-90.8)$ & $(57.0-76.4)$ \\
\hline \multirow[t]{2}{*}{$>680^{* *}$} & & $0(0)$ & & 2.5 & & 6.1 & & 9.3 & & 4.5 & 7.1 & \\
\hline & & & & $(0.3-16.8)$ & & $(2.9-12.1)$ & & $(4.8-17.1)$ & & $(2.3-8.6)$ & (3.7-13.3) & \\
\hline \multicolumn{13}{|c|}{ Folates (nmol/L) } \\
\hline$n$ & 64 & 48 & 66 & 52 & 180 & 157 & 179 & 137 & 244 & 205 & 245 & 189 \\
\hline$<7$ & 0 & 0 & 0 & 0 & 0 & 0 & 0 & 0 & 0 & 0 & 0 & 0 \\
\hline \multirow[t]{2}{*}{$7-46$} & 79.7 & 91.7 & 89.4 & 90.4 & 77.2 & 92.4 & 77.6 & 95.6 & 77.9 & 92.2 & 80.8 & 94.2 \\
\hline & $(67.8-88.7)$ & $(80.0-97.7)$ & $(79.4-95.6)$ & $(79.0-96.8)$ & $(70.4-83.1)$ & $(87.0-96.0)$ & $(70.8-83.5)$ & $(90.7-98.4)$ & $(72.1-82.9)$ & $(87.6-95.4)$ & $(75.3-85.5)$ & $(89.8-97.0)$ \\
\hline \multirow[t]{2}{*}{$>46$} & 20.3 & 8.3 & 10.6 & 9.6 & 22.8 & 7.6 & 22.3 & 4.4 & 22.1 & 7.8 & 19.2 & 5.8 \\
\hline & $(11.3-32.2)$ & $(2.3-20.0)$ & $(4.4-20.6)$ & $(3.2-21.0)$ & $(16.9-29.6)$ & $(4.0-13.0)$ & $(16.5-29.2)$ & $(1.6-9.3)$ & $(17.1-27.9)$ & $(4.5-12.4)$ & $(14.4-24.7)$ & $(2.9-10.1)$ \\
\hline
\end{tabular}

B12* Test $x 2:$ Men: $p=0.69 ;$ Women: $p=0.80 ;$ Total $p=0.72$. **Test $x 2:$ Men: $p=0.61 ;$ Women: $p=0.76$; Total $p=0.59$. Folates ${ }^{*}$ Test $x 2:$ Men: $p=0.21 ;$ Women: $p=0.96 ;$ Total $p=0.72$. **Test $x 2:$ Men: $p=0.85 ;$ Women: $p=0.25$; Total $p=0.55$; **High Level excluded analysis baseline. 
of B12 in older adults is above the daily-recommended allowance.

After the intervention, the folate levels decreased in both groups, showing that PACAM fortification with folic acid has little or no effect. Taking into account that the absorption of folic acid is not influenced by age, and bread consumption in Chile is very high in all groups of age, it is possible to postulate that this decrease is due to a reduction in the amount of folic acid in wheat flour during the years when the CENEX study was carried out, as described by Castillo [15].

In Chile, the National Program of Complementary Feeding for the Elderly over the age of 70 provides $45.8 \%$ of the daily-recommended intake of B12. Our findings show that this amount does not ensure that this population maintains adequate levels of B12. Therefore, it is important to address a number of questions regarding the nutritional programs implemented in our country: First, we should evaluate the true amount of micronutrients provided by the foods included in these programs. Second, we should evaluate the effectiveness of fortifying PACAM products with crystalline B12 in quantities greater than the RDA. Finally, we should review existing B12 recommendations for this age group.

There is an international consensus on the need to target B12 in particular in nutrition interventions for older adults if foods are universally fortified with folic acid [34].

Chile has a long and successful experience in nutrition intervention programs; however, the country's changing demographic, epidemiologic and nutritional profile requires a constant surveillance of the nutritional programs, carrying out periodic evaluations of the programs' impact on the target population.

The high burden of illness associated with chronic nutrition-related diseases on a global and national level significantly affects national health budgets. This makes it even more important to evaluate the interventions and identify the most cost-effective course of action [35], without losing sight of the fact that nutrition and physical activity are fundamental for maintaining an active, healthy, and autonomous lifestyle and high quality of life for older adults.

\section{Competing interests}

The authors declare that they have no competing interests.

\section{Authors' contributions}

$\mathrm{HS}$ and CA conceived the study. RU, CA, AD, HS applied for funding. All authors contributed to designing the study. HS, CA, AD, RU and LL critically reviewed and revised the manuscript. All authors read and approved the final manuscript.

\section{Funding}

Funding provided by: The Wellcome Trust, grant number 075219; Chilean National Fund for Science and Technology (FONDECYT) grant number 1070592.

\section{Author details}

'Nutrition and Public Health, Aging, and Genetic Epidemiology Unit, Institute of Nutrition and Food Technology, University of Chile, Avda. El Libano 5524, Casilla 138-11, Santiago, Chile. ${ }^{2}$ Department of Population Health, Faculty of Epidemiology and Population Health, London School of Hygiene \& Tropical Medicine, London, UK.

Received: 18 December 2012 Accepted: 31 July 2013

Published: 9 September 2013

\section{References}

1. Albala C, Vio F, Kain J, et al: Nutrition transition in Latin America: The case of Chile. Nutr Reviews 2001, 56:170-176.

2. Palloni A, Pinto-Aguirre G, Pelaez M: Demographic and health conditions of ageing in Latin America and the Caribbean. Int J Epidemio/ 2002, 31(4):762-771. PubMed PMID: 12177016.

3. Berry E: Chronic disease: How can nutrition moderate the effects? Nutr Reviews 1994, 52(Suppl 2):28-30.

4. Carmel R: Nutritional anemias and the elderly. Semin Hematol 2008 Oct, 45(4):225-234

5. Carmel R, Green R, Rosenblatt DS, et al: Update on cobalamin, folate, and homocysteine. Haematology Am Soc Hematol Educ Program 2003, 62:81.

6. Sánchez H, Albala C, Hertrampf E, et al: Déficit de vitamina B-12 en adultos mayores:¿Un problema de salud pública en Chile? Rev Med Chile 2010, 138:56-61.

7. Olivares M, Hertrampf E, Capurro MT, et al: Prevalence of anaemia in elderly subjects living at home: role of micronutrient deficiency and inflammation. Eur J Clin Nutr 2000, 54:834-839.

8. Hirsch S, De la Maza P, Barrera G, et al: The Chilean Flour Folic Acid Fortification program reduces serum homocysteine levels and masks B12 deficiency in elderly people. J Nutr 2002, 132:289-291.

9. Mardones SF: Algunos antecedentes sobre la inequidad en la situación de salud del adulto mayor en Chile. Rev. Méd. Chile 2004, 132(7):865-872.

10. Ministerio de Salud: Programa de Salud del Adulto Mayor, Norma General Técnica №39 aprobada por Resolución Exenta № 1293 de fecha. 1999. Available at: http://www.minsal.gob.cl/portal/url/item/635f0244d397c239e04 001011e016c98.pdf.

11. Ministerio de Salud: Objetivos Sanitarios para la década 2000-2010. Chile: Santiago; 2002. Available at: http://www.redsalud.gov.cl/portal/url/item/ 8f25c1f0b06d303fe04001011e014be4.pdf.

12. Ministerio de Salud: Programa de Alimentación Complementaria del Adulto Mayor. Santiago Chile; 1999. Available at: http://www.redsalud.gov.cl/portal/ url/item/8f25c1f0b06d303fe04001011e014be4.pdf.

13. Dangour A, Moreno X, Albala C, et al: Chile's national nutritional supplementation program for older people: lessons learned. Food Nutr Bull 2005, 26:190-7.

14. de Chile M d S: Norma Técnica para la fortificación de la Harina de Trigo con Vitaminas y Minerales. Diciembre de 1999

15. Castillo C, Tur JA, Uauy R: Flour fortification with folic acid in Chile. Unintended consequences. Rev Med Chil 2010, 138(7):832-840.

16. Dangour AD, Albala C, Allen E, et al: Effect of a nutrition supplement and physical activity program on pneumonia and walking capacity in Chilean older People: A factorial cluster randomised trial. PLOS Med 2011, 8:1001023. doi:10.1371 / journal. pmed.1001023.

17. Dangour AD, Albala C, Aedo C, et al: A factorial-design cluster randomised controlled trial investigating the cost-effectiveness of a nutrition supplement and an exercise programme on pneumonia incidence, walking capacity and body mass index in older people living in Santiago, Chile: the CENEX study protocol. Nutr J 2007, 6:14-18.

18. Folstein MF, Folstein SE, McHugh PR: Mini-mental state. A practical method for grading the cognitive state of patients for the clinician. J Psychiatr Res 1975, 189:198.

19. Pfeffer Rl, Kurosaki TT, Harrah CH Jr, Chance JM, Filos S: Measurement of functional activities in older adults in the community. J. Gerontol 1982, 37:323-329.

20. Quiroga P, Albala C, Klaasen G: Validación de un test de tamizaje para el diagno'stico de demencia asociada a edad, en Chile. Rev Med Chil 2004, 132:467-478.

21. Institute of Medicine: Dietary Reference Intakes for Thiamin, Riboflavin, Niacin, Vitamin B6, Folate, Vitamin B12, Pantothenic Acid, Biotin, and Choline. A Report of the Standing Committee on the Scientific 
Evaluation of Dietary Reference Intakes and its Panel on Folate, Other B Vitamins, and Choline and Subcommittee on Upper Reference Levels of Nutrients, Food and Nutrition Board, Institute of Medicine. National Academies Press 1998.

22. Allen L: Folate and vitamin B-12 Status in the Americas. Nutr Reviews 2004, 62:S29-S33.

23. Morris MS, Jacques PF, Rosenberg $\mathrm{HH}$, et al: Folate and vitamin B-12 status in relation to anaemia, macrocytosis, and cognitive impairment in older Americans in the age of folic acid fortification. Am J Clin Nutr 2007, 85:193-200

24. Clarke R, Evans G, Schneede J, et al: Vitamin B-12 and folate deficiency in later life. Age Ageing 2004, 33:34-41.

25. WHO/UNICEF/UNU: Iron deficiency anaemia assessment prevention, and control: a guide for programme managers. Geneva, Switzerland: World Health Organisation; 2001

26. Andrès $E$, Loukili NH, Noel E, Kaltenbach $G$, Abdelgheni $M B$, Perrin $A E$, et al: Vitamin B12 (cobalamin) deficiency in elderly patients. CMAJ 2004 171(3):251-9.

27. Allen LH: How common is vitamin B-12 deficiency? Am J Clin Nutr 2009, 89:693-696.

28. Loikas S, Koskinen P, Irjala K, Löppönen M, Isoaho R, Kivelä S-L, Pelliniemi T-T: Vitamin B12 deficiency in the aged: a population-based study. Age Ageing 2007, 36(2):177-83.

29. Russell RM: Changes in gastrointestinal function attributed to aging. Am J Clin Nutr 1992, 55:1203S-1207S.

30. Miller A, Furlong D, Burrows BA, et al: Bound vitamin B12 absorption in patients with low serum B-12 levels. Am J Hematol 1992, 40:163-166.

31. Scarlett JD, Read H, O'Dea K: Protein-bound cobalamin absorption declines in the elderly. Am J Hematol 1992, 39:79-83.

32. Sánchez H, Albala C, Lera L, Castillo JL, Verdugo R, Lavados M, Hertrampf E, et al: Comparison of two modes of vitamin B12 supplementation on neuroconduction and cognitive function among older people living in Santiago, Chile: A cluster randomised controlled trial. A study protocol [ISRCTN 02694183]. Nutr J 2011, 10(1):100. BioMed Central Ltd. doi:10.1186/ 1475-2891-10-100.

33. Campbell A, Millar J, Green R, et al: Plasma Vitamin B-12 concentrations in an Elderly Latino population are predicted by serum Gastrin concentrations and crystalline vitamin B-12 intake. J Nutr 2003, 133:2770-2776.

34. Johnson MA: If high folic acid aggravates vitamin B-12 deficiency what should be done about it? Nutr Rev 2007, 65:451-8.

35. Christensen K, Doblhammer G, Rau R, Vaupel JW: Ageing populations: the challenges ahead. Lancet 2009, 374:1196-208.

\section{Submit your next manuscript to BioMed Central and take full advantage of:}

- Convenient online submission

- Thorough peer review

- No space constraints or color figure charges

- Immediate publication on acceptance

- Inclusion in PubMed, CAS, Scopus and Google Scholar

- Research which is freely available for redistribution 